\title{
Laser-Induced Breakdown Spectroscopy Applied on Liquid Films: Effects of the Sample Thickness and the Laser Energy on the Signal Intensity and Stability
}

\author{
Violeta Lazic and Massimiliano Ciaffi \\ Department of FSN-TECFIS-DIM, ENEA, Via E. Fermi 45, 00044 Frascati, Italy \\ Correspondence should be addressed to Violeta Lazic; violeta.lazic@enea.it
}

Received 28 June 2017; Accepted 4 October 2017; Published 1 November 2017

Academic Editor: Nikša Krstulović

Copyright (c) 2017 Violeta Lazic and Massimiliano Ciaffi. This is an open access article distributed under the Creative Commons Attribution License, which permits unrestricted use, distribution, and reproduction in any medium, provided the original work is properly cited.

\begin{abstract}
Droplets of organic liquids on aluminum substrate were probed by an Nd:YAG laser, both in a steady state and during rotation at speeds 18-150 rpm. Rotation transforms the droplet into film, which estimated thickness at high speeds was below $3 \mu \mathrm{m}$ and $20 \mu \mathrm{m}$ for diesel and peanut oil, respectively. Line intensities from the liquid (C I) and the support (Al I) material were tracked as a function of the film thickness and the laser energy. By film thinning, the line intensities from liquid sample were enhanced up to a factor 100x; simultaneously, the LIBS signal fluctuations were reduced 5-10 times with respect to the steady droplet. In certain experimental conditions, the line intensities from the support material become very weak with respect to the C I line, indicating an efficient screening of the substrate by highly excited plasma from the liquid layer. At a fixed rotation speed, there is a laser energy threshold, dependent on the liquid thickness, above which the LIBS signal becomes stable. Here, we discuss the relative processes and optimization of the experimental conditions for the LIBS measurements frome one laser shot to another.
\end{abstract}

\section{Introduction}

Laser-induced breakdown spectroscopy (LIBS) provides information about elemental composition of the sample volume involved in the plasma [1-3]. LIBS could be applied for analysis of materials in solid, liquid, and gaseous state, as well as of aerosols [4-6] and of particles suspended in liquid media $[7,8]$.

Rapid chemical analysis of liquids by LIBS [9] has many potential applications; among them, there are monitoring of waters [10-13], of quality in pharmaceutical or food industry [14-16], medical diagnostics [17, 18], and control of industrial processes or mechanical equipment [19, 20]. Laser-induced plasma on or inside liquids generates intense shockwaves, bubbling, and expulsion of droplets, which together with the laser energy losses due to liquid vaporization reduce the available energy for the plasma excitation. LIBS measurements on liquids usually have low analytical sensitivity, which could be improved by proper experimental approach and sample preparation, as reviewed in $[9,21]$ and updated in $[22]$.
Excluding some complex methods for preparation of liquid samples that eliminate advantages of LIBS in terms of simplicity, rapidity, and possibility for in-field measurements, on evaporating liquids (like waters and alcohols), an intense LIBS signal could be obtained by probing the residues left on a solid substrate $[13,14,18,23]$. The sample drying should be performed close to room temperature in order to prevent losses of volatile components. This process is timeconsuming, it leaves not uniform residue distribution, and it could not be applied on liquids like oils.

Recently, another simple approach for LIBS measurements of liquids has been reported and it regards the signal generation on a thin liquid film placed over an absorbing substrate $[22,24]$. Here, the breakdown initiates on the substrate and the plasma atomizes and ionizes the liquid layer. In this way, the laser-induced splashes, the plasma formation threshold, and the matrix effect (very strong in case of a direct plasma formation on liquids [9]) are importantly reduced. The LIBS signal strongly gains in intensity and so in analytical sensitivity. 
Xiu et al. [24] prepared a thin oil film of arbitrary thickness on aluminium substrate by spreading manually the liquid. The plasma distribution in terms of intensity, temperature, and electron density was studied comparatively on dry aluminium and the same was covered with the oil film. It was noticed that on bare aluminium, the plasma remains close to the target surface while in presence of a thin liquid film, the maximum plasma emissivity is shifted away from the surface for a $1.5-2 \mathrm{~mm}$. Vapor confinement by the initial liquid layer, later transformed to the plume, produces the plasma temperature and the electron density higher than in the case of the uncovered substrate.

Well controlled and reproducible oil film thickness could be obtained by rotating substrate at adjustable speed or by electrowetting on dielectric with controlled voltage in case of water solution [22]; the latter is impossible to thin by rotation due to high cohesive forces. This is the only work that reports changes of the LIBS signal with thickness of a liquid film. It was found that progressive thinning of a liquid film first eliminates the laser-induced splashes than the aerosol expulsion, and up to a certain thickness, it increases the emission lines from elements present in the liquid. However, the systematic studies of influence of liquid film height over substrate on the LIBS signal have not been yet performed although such sampling method, simple and applicable also for small sample volumes, could lead to a huge increase in the detection sensitivity [22].

For comparison, when analyzing water solutions in form of thin liquid sheet in air, it was found that the LIBS line intensities increase up to the sheet thickness of $20 \mu \mathrm{m}$ [25], and this was explained by the largest liquid-laser interaction volume. For major sheet thicknesses, the LIBS signal decreases due to larger energy losses into mechanical effects and liquid evaporation. For a fixed liquid jet thickness, there is an optimal laser energy for the LIBS signal strength and the further energy growth reduces both the line intensities and their shot-to-shot stabilities [26].

On the other hand, it is well known that the efficiency of wet laser ablation (LA), particularly important for medicine and nanoparticle production, depends on a liquid type and its height above the solid target. In [27], by using $\mathrm{KrF}$ laser, the highest ablation rate of silica covered with water was obtained for the liquid layer of $1.1 \mathrm{~mm}$, corresponding to the strongest local pressure induced by the laser. In LA of a bone covered by $1 \mathrm{~mm}$ thick water layer, it was observed that increase of the laser fluency above a certain level does not increase the ablation rate because of the plasma shielding [28]. For LA of aluminium by an Nd:YAG laser at $1064 \mathrm{~nm}$, the optimum water thickness was of $3 \mathrm{~mm}$, producing a 28 -fold increase in crater volume compared to ablation in air [29]. In LA of zirconia by fs pulses, the highest ablation rate in presence of acetone was achieved for the liquid height between 0.2 and $0.7 \mathrm{~mm}$ [30]. At fixed experimental conditions, the film thickness for the maximum target ablation depends on the liquid properties [31].

There are also several works that explain laser-induced detachment of a thin liquid film from a solid-absorbing target [32]. Below the threshold for the plasma formation, the laser pulse rapidly rises temperature at the liquid-solid interface, creating a high-pressure vapor layer that expels the thin film from the surface. However, in scientific literature, there is a lack of knowledge relative to the plasma formation involving a liquid film over absorbing substrate and how the optical emission depends on the experimental conditions.

In the present work, we study LIBS signal behavior as a function of the estimated liquid film thickness over aluminium substrate and influence of the laser pulse energy. The examined liquids are diesel and peanut oil, chosen due to very different kinematic viscosities, which determine the liquid film thickness after the substrate rotation at a certain speed. The line intensities and their shot-to-shot fluctuations were considered for both $\mathrm{Al}$ I and $\mathrm{CI}$ emissions relative to the substrate material and the liquid, respectively.

\section{Experimental}

2.1. Instruments and Layout. Figure 1 shows the experimental layout, where the plasma was generated by an Nd:YAG laser (Quantel, CFR Ultra) emitting $6.5 \mathrm{~ns}$ long pulses at $1064 \mathrm{~nm}$. The laser beam, without or after passing a beam splitter that transmits about $34 \%$ of the incident energy, was focused perpendicularly to the sample by means of a plano-convex quartz lens with focal length $f=100 \mathrm{~mm}$. The spot diameter on the sample, placed slightly above the focal plane, was of about $0.42 \mathrm{~mm}$, and it was determined on silica wafer. The LIBS measurements were performed with the incident laser energy between $18 \mathrm{~mJ}$ and $190 \mathrm{~mJ}$, corresponding to the irradiance $2-21 \mathrm{GW} / \mathrm{cm}^{2}$.

The plasma emission was collected at angle of about $60^{\circ}$ from the target plane by two quartz lenses (focal lengths $100 \mathrm{~mm}$ and $70 \mathrm{~mm}$ ) and brought to a spectrometer (JobinYvon 550), used here with grating $1200 \mathrm{gr} / \mathrm{mm}$, by a fiber bundle arranged at the exit into $0.1 \mathrm{~mm} \times 12.2 \mathrm{~mm}$ array. At the spectrometer's output, an ICCD (Andor iStar DH734) was used for the LIBS signal detection. The acquisition gate and delay from the laser pulse were adjusted by a delay generator (Quantum Composer 9600+) to values of $2 \mu \mathrm{s}$ and $1.2 \mu \mathrm{s}$, respectively. The measurements were performed at the laser repetition rate limited to $2 \mathrm{~Hz}$.

Images of the plasma and of the liquid droplet/film were taken by a commercial photographic camera. The contact area between the liquid and the support material was determined from dimensionally calibrated photographs with help of ImageJ software (free source). The average liquid thickness on the substrate was calculated from the measured area occupied by the droplet and the known, deposited sample volume.

2.2. Samples and Preparation. Liquids used in the experiment are a commercial diesel fuel and a refined edible peanut oil. These two liquids were chosen due to very different kinematic viscosities (see Table 1), which produce large differences in the liquid film thicknesses on the substrate.

As a substrate, we used an aluminum disk with diameter of $25 \mathrm{~mm}$, matching the spin coater. If not specified differently in the text, aluminium surface was polished by a sandpaper 400 grits/mm but for some measurements, we also tested the surface polished with 800 grits $/ \mathrm{mm}$. Before placing a liquid 


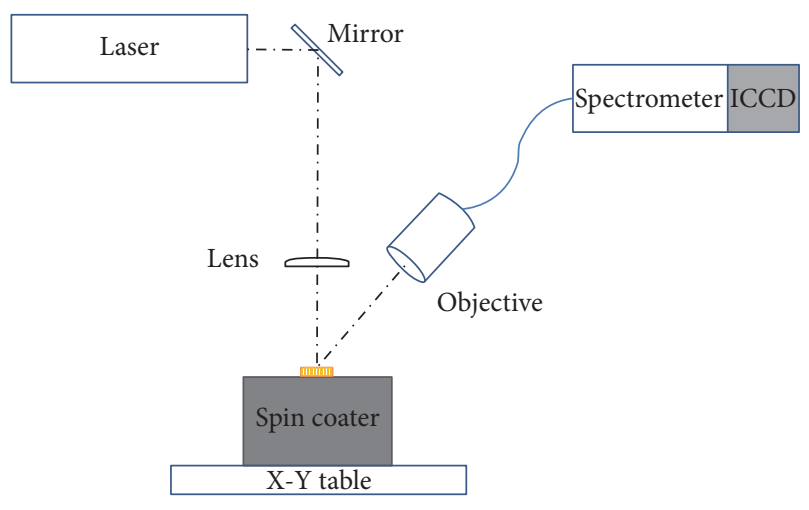

FIgURE 1: Experimental layout.

droplet on the substrate, the same was washed in a water flux, dried, and then washed by a high-purity methanol.

Liquid sample placed on the substrate had precisely controlled volume $( \pm 1 \%)$, delivered by an autoclavable pipette (Labgene Scientific). A droplet placed at the disc center was spread into a film by rotating the substrate on a spin coater (Laurell Technologies, KL-SCI-20), which speed can be adjusted between 18 and $150 \mathrm{rpm}$. After turning on the spin coater and before starting the LIBS measurements or stopping the rotation to photograph the film surface, we waited at least $30 \mathrm{~s}$ to stabilize first the rotation speed and successively the liquid film thickness.

Although the LIBS measurements could be performed on a single droplet of a few microliters, here, we used larger sample volumes, sufficient to cover completely the aluminium disk. At low rotation speed $(<25 \mathrm{rpm})$, the excess of the liquid accumulates at the support edges; otherwise, it escapes from the surface. The sampling was performed during the rotation, by registering separately the spectra produced by 10 laser pulses. Between the two LIBS measurements, the whole holder was shifted horizontally for $2 \mathrm{~mm}$ in order to avoid development of the craters on support material, and another $10 \mu \mathrm{L}$ droplet was added, waiting again $30 \mathrm{~s}$ to stabilize the liquid film thickness.

\section{Results}

3.1. Effects of the Rotation Speed. On the steady aluminum support, a $20 \mu \mathrm{L}$ droplet has the average thickness over the contact area of about $140 \mu \mathrm{m}$ and $320 \mu \mathrm{m}$ for diesel and peanut oil, respectively (Table 1). Due to a meniscus shape of the droplet, in the central part where the laser beam was focused, the local thickness is about twice larger than the average value. On diesel droplets, we studied the LIBS signal behavior as a function of the rotation speed at two different laser energies, namely, $23 \mathrm{~mJ}$ and $70 \mathrm{~mJ}$. In absence of rotation, the laser pulse, even at the low energy $(23 \mathrm{~mJ})$, produces splashes that reach the nearby optical elements, so it was necessary to clean them after each laser shot. The LIBS spectrum from the steady droplet shows rather weak spectral lines (Figure 2(a)) from both the liquid (C I) and the support material ( $\mathrm{Al} \mathrm{I}$ and Si I). After switching on the spin coater at its minimum speed (18 rpm), the splashes disappear but there is some aerosol spraying, which deposition on the nearby optical components was visible after a few tenths of the laser pulses. For this reason, at low rotation speed, the lenses were cleaned after each 10 laser shots. At $18 \mathrm{rpm}$, the LIBS signal is about 20 times more intense than in the case of the steady droplet (Figure 2(b)). Further increase of the rotation speed leads to disappearance of the aerosol, and for the speed of $40 \mathrm{rpm}$ or higher, the optical elements did not require periodical cleaning. At the rotation speed of $100 \mathrm{rpm}$, where the estimated liquid film thickness was in order of a few $\mu \mathrm{m}$ (Table 1), the spectral lines are about 100 times more intense compared to the steady droplet. Here, also the emission lines from Mn II and Fe II around $260 \mathrm{~nm}$ were clearly observed, indicating the method's capability to detect also minor sample constituents even by applying a relatively low laser energy.

Figure 3 shows the average intensities of C I $(247.8 \mathrm{~nm})$ and $\mathrm{Al} \mathrm{I}(256.8 \mathrm{~nm})$ lines and their relative standard deviations (RSDs) as a function of the rotation speed for pulse energies of $23 \mathrm{~mJ}$ and $70 \mathrm{~mJ}$. By using the lower pulse energy, the line intensities from both C I and Al I steadily grow in range $25-90 \mathrm{rpm}$, and then the saturation occurs. At this point, the liquid film is probably fully evaporated locally and efficiently atomized by the laser pulse; thus, its further thinning does not contribute to the signal intensity. RSD of the characteristic lines rapidly decays with disappearance of the splashes, that is, passing from a thick droplet to a liquid film. However, RSD of C I line keeps at high values, around 0.5 , up to the speed of $90 \mathrm{rpm}$ where the LIBS signal saturates. For the faster rotation, the RSD oscillates around value of 0.2 . At the higher laser energy $(70 \mathrm{~mJ})$, the LIBS signal growth is much slower than in the previous case, and C I line intensity becomes almost saturated starting from about $50 \mathrm{rpm}$. For the same speed, the RSD of the C I line drops down and then oscillates around value of 0.1 . This value of RSD was obtained also for $\mathrm{Al} \mathrm{I}$ lines from the rotating support uncovered by a liquid, and we hypothesize that the vibrations present during rotation keep the LIBS signal fluctuations at this limit. From the obtained results here, we might conclude that there exists a threshold thickness of liquid film below which the laser pulse produces a full local sample evaporation and a more stable LIBS signal. This threshold thickness and the LIBS signal stability relative to the liquid increase with the laser energy. From Figures 3(a) and 3(b), we might note that the ratio of $\mathrm{C} \mathrm{I}$ and $\mathrm{Al} \mathrm{I}$ line intensities is higher at higher pulse energy, and this will be discussed later.

In analyzing behavior of the $\mathrm{Al} \mathrm{I}$ at $256.8 \mathrm{~nm}$, some cautions must be taken as this line is resonant, although much less intense than the nearby line at $257.5 \mathrm{~nm}$, and a self-absorption might occur. The experimentally measured ratio of these two lines for the data shown in Figure 3 was in range $0.58-0.59$ while their predicted ratio from the NIST database should be about 0.36 according to the formula valid for the plasma in local thermal equilibrium:

$$
I^{k i}=a \cdot N \frac{g_{k} A_{k i} e^{-\left(\left(E_{k}\right) / k\right) T}}{U(T)},
$$

where $a$ is constant depending on experimental conditions; $g_{k}$ and $A_{k i}$ are the level degeneracy and the tabulated transition probability, respectively; $E_{k}$ is energy of the upper 
TABLe 1: Physical properties and the estimated droplet/film thicknesses for diesel and peanut oil.

\begin{tabular}{lcc}
\hline & Diesel & Peanut oil \\
\hline Surface tension at $20^{\circ} \mathrm{C}(\mathrm{mN} / \mathrm{m})$ & $25.8[33]$ & $10.0[34]$ \\
Kinematic viscosity $\left(\mathrm{mm}^{2} / \mathrm{s}\right)$ at $40^{\circ} \mathrm{C}$ & $2-4^{*}$ & $37[35]$ \\
Average thickness of $20 \mu \mathrm{L}$ droplet $(\mu \mathrm{m})$ & $141 \pm 10$ & $320 \pm 20$ \\
Av. thickness of droplet $5 \mu \mathrm{L}$ at $18 \mathrm{rpm}(\mu \mathrm{m})$ & $19 \pm 4$ & $\leq 2 \pm 10$ \\
Av. thickness of liquid film at $100 \mathrm{rpm}(\mu \mathrm{m})^{* *}$ & $\leq 3.0$ & $\leq 20$ \\
\hline
\end{tabular}

* means specified by the supplier. ** means measured for droplet volumes of $0.2 \mu \mathrm{L}$ and $5 \mu \mathrm{L}$ for diesel and oil, respectively.

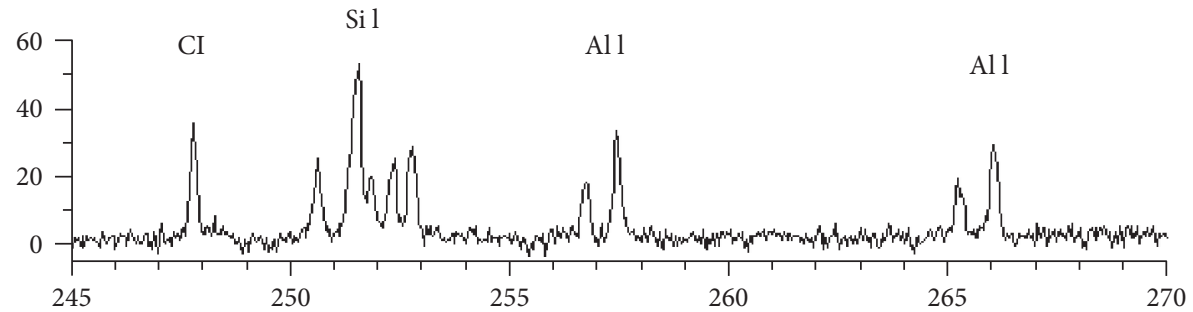

(a) Steady

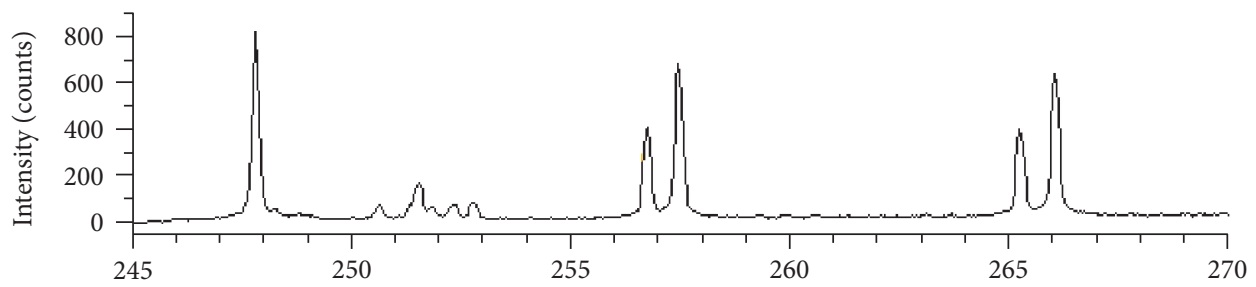

(b) $18 \mathrm{rpm}$

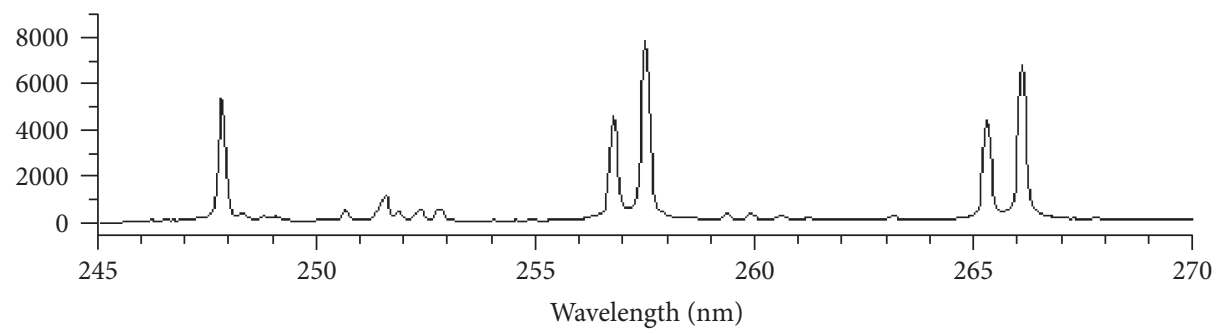

(c) $100 \mathrm{rpm}$

FIGURE 2: LIBS spectra from diesel, averaged over 10 laser pulses with energy of $23 \mathrm{~mJ}$. Steady droplet (a) and support rotated at $18 \mathrm{rpm}$ (b) and $100 \mathrm{rpm}(\mathrm{c})$.

transition level, $U(T)$ is the temperature dependent partition function of the considered species with density $N$ in the plasma. The low measured ratio of the two Al I (doublet) means that the more intense transition (257.5) is selfabsorbed. We do not know if and how much the less intense line is self-absorbed but the stable line intensity ratio from the doublet in different experimental conditions indicates that behavior of the chosen Al I line $(256.8 \mathrm{~nm})$ in Figure 3 is not caused by the line saturation.

We performed the analog measurements on peanut oil, which a droplet leaves much thicker liquid film with respect to diesel (Table 1), by applying the laser energy of $70 \mathrm{~mJ}$. Also in this case, the intensity of $\mathrm{C}$ I line becomes more stable close to the rotation speed of $50 \mathrm{rpm}$ (Figure 4) but the corresponding RSD is about three times higher than in the case of diesel (see Figure 3(d)). For the steady droplet, the RSD is much higher than the same one measured on diesel, and it decreases below 1.0 only at speed of about $35 \mathrm{rpm}$.

In the following, we attempted to estimate the average liquid film thickness as a function of the rotation speed. To this aim, we placed on the substrate a droplet with well-controlled volume $\mathrm{V}(\mu \mathrm{L})$ and then measured the area $A\left(\mathrm{~mm}^{2}\right)$ occupied by the droplet/liquid film after performing dimensional image calibration. The average liquid thickness $d(\mu \mathrm{m})$ was then calculated as $d=V(\mu \mathrm{L}) / A\left(\mathrm{~mm}^{2}\right)$. In absence of rotation, the error in estimating $A$ is low as the liquid is clearly encircled also when photographing the sample perpendicularly to the support (Figure 5(a)). If the liquid reaches borders of the support (Figure 5(b)), the estimated average film thickness could be higher than the real one as the losses of liquid volume 

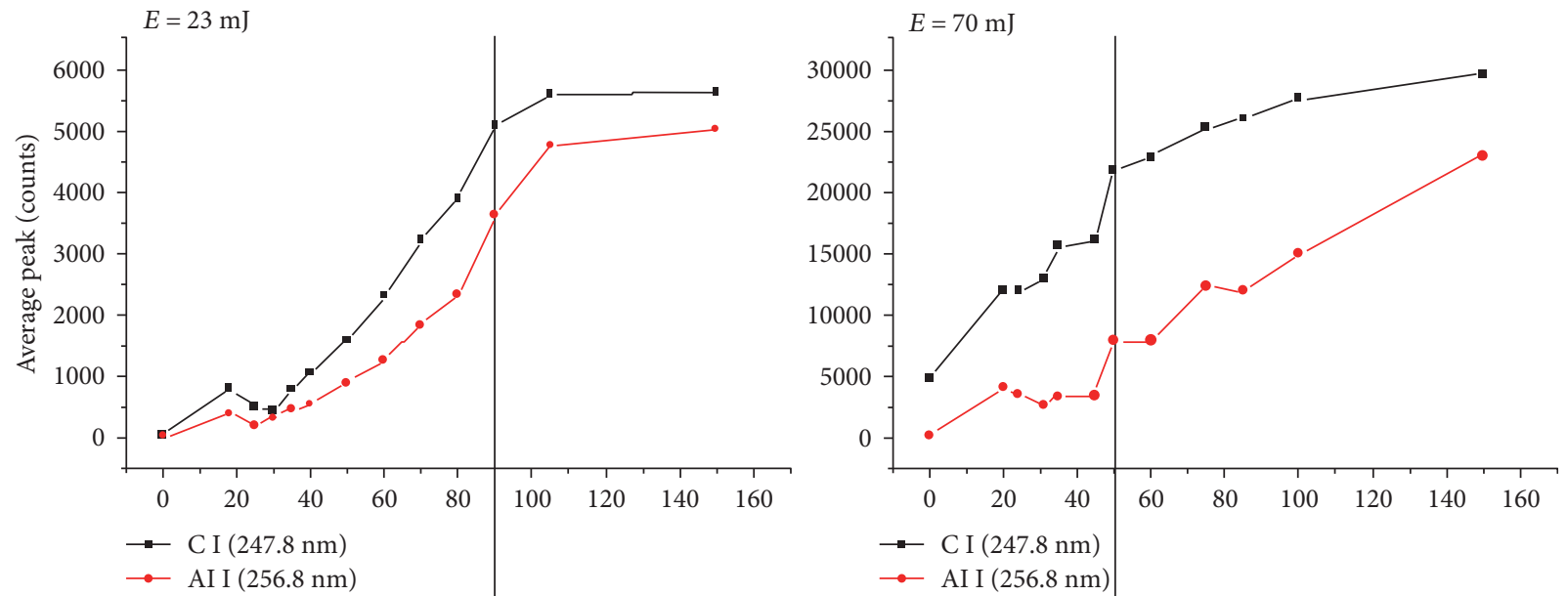

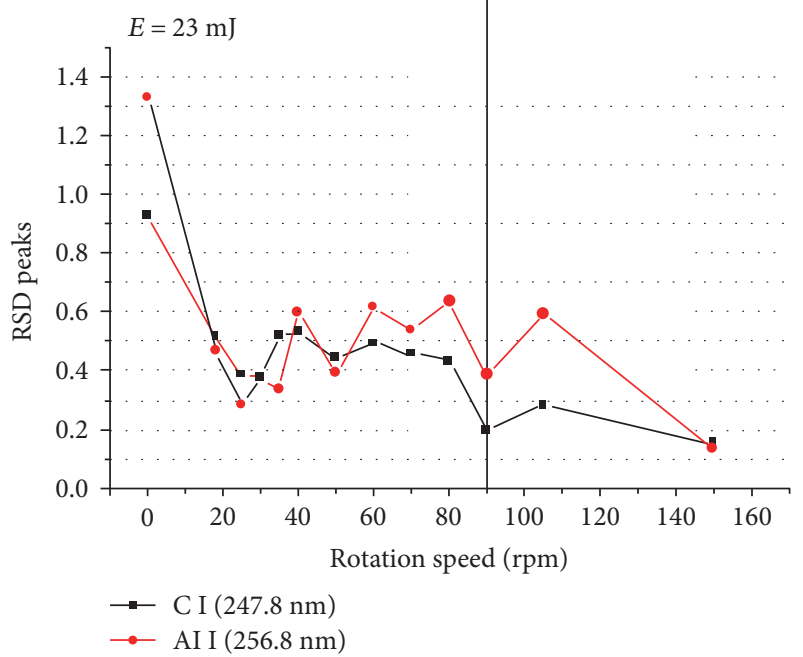

(c)

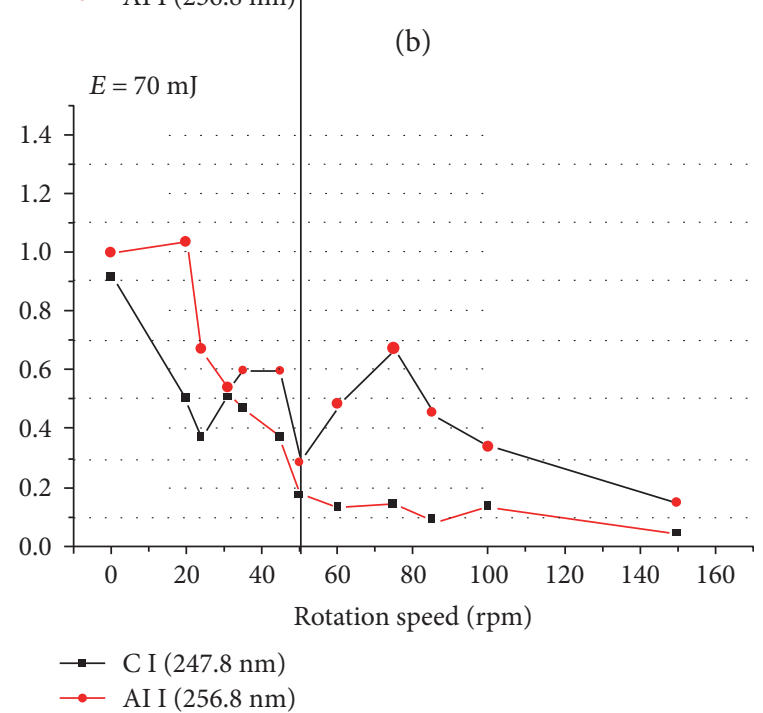

(d)

FIGURE 3: Average peak intensity of C I and $\mathrm{Al}$ I lines from the diesel droplet, measured over 10 pulses, as a function of the rotation speed for laser energies of $23 \mathrm{~mJ}$ (a) and $70 \mathrm{~mJ}$ (b); the corresponding RSD is shown in (c) and (d), respectively.

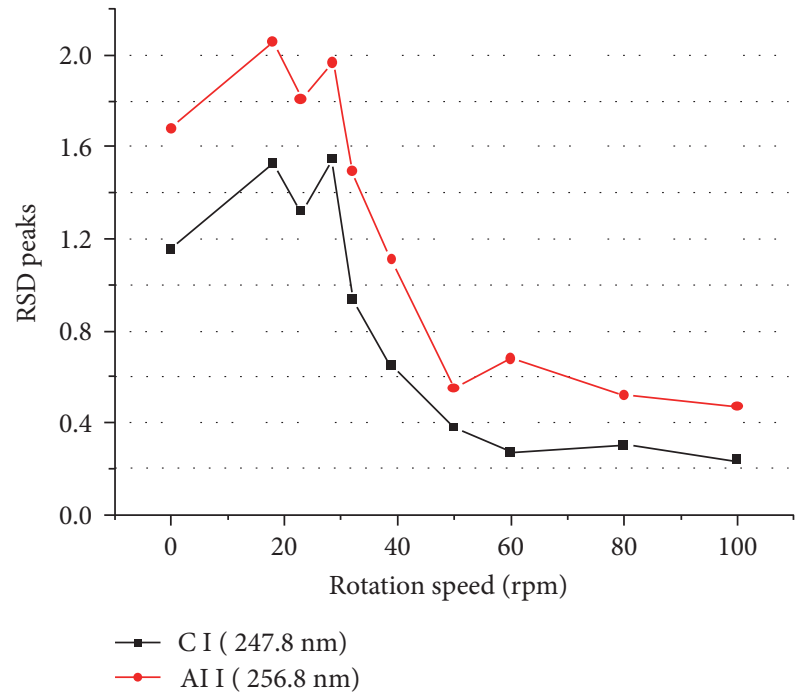

FIGURE 4: RSD of C I and Al I lines from $20 \mu \mathrm{L}$ droplet of peanut oil as a function of the rotation speed; the laser energy is $70 \mathrm{~mJ}$. from the substrate might occur. By applying high rotation speeds, the shape of area occupied by liquid becomes irregular, introducing larger errors in its circle, and it was necessary to take the photographs angularly-this also increases the error due to the perspective (Figure 5(c)).

Initially, we attempted to determine the film thickness of $20 \mu \mathrm{L}$ oil droplet but the liquid reaches the borders of the support already at the rotation speed of $18 \mathrm{rpm}$ (Figure 5(b)). Further increase of the rotation speed causes losses of the liquid, visibly sputtered away from the support, and to a consequent overestimation of the average film thickness, based on the known deposited liquid volume. For this reason, the measurements of the oil film thickness were performed also for the droplet of $5 \mu \mathrm{L}$, on the substrate polished with sandpaper of 400 grits $/ \mathrm{mm}$ or 800 grits $/ \mathrm{mm}$ (Figure 6). For the substrate polishing by 400 grits $/ \mathrm{mm}$, at the rotation speed of $18 \mathrm{rpm}$ the droplet of $20 \mu \mathrm{L}$ has the average thickness similar to that of the smaller droplet $(5 \mu \mathrm{L})$. However, by the applied method here, the estimated film thickness at larger rotation speed differs significantly in the two cases due to the liquid volume loss that affects calculations of the average 


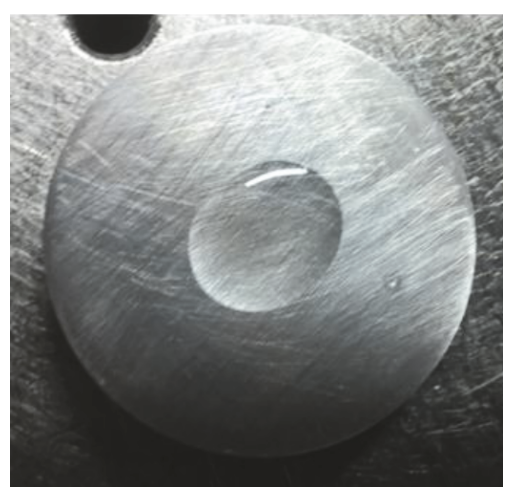

(a)

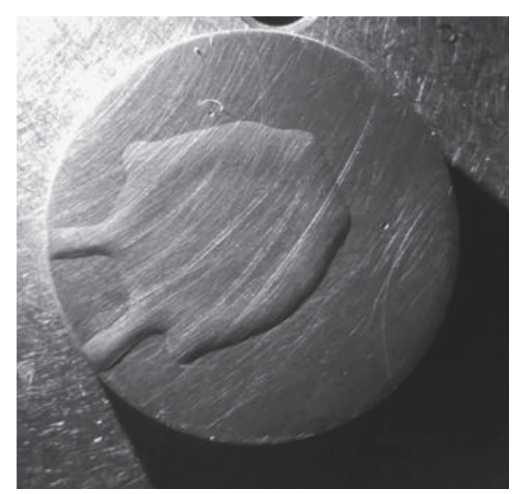

(b)

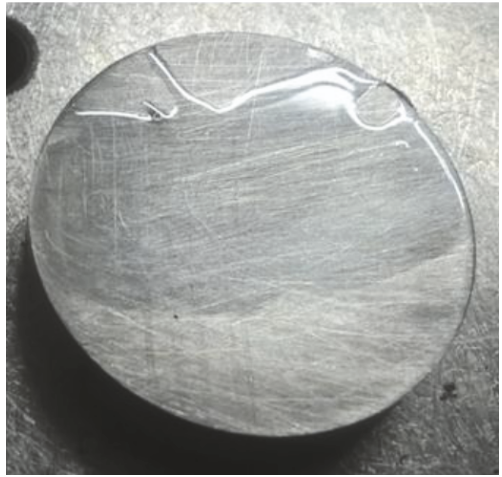

(c)

Figure 5: Photos of $20 \mu \mathrm{L}$ oil droplet on (a) steady support; after rotating at $18 \mathrm{rpm}$ (b) and $45 \mathrm{rpm}$ (c).

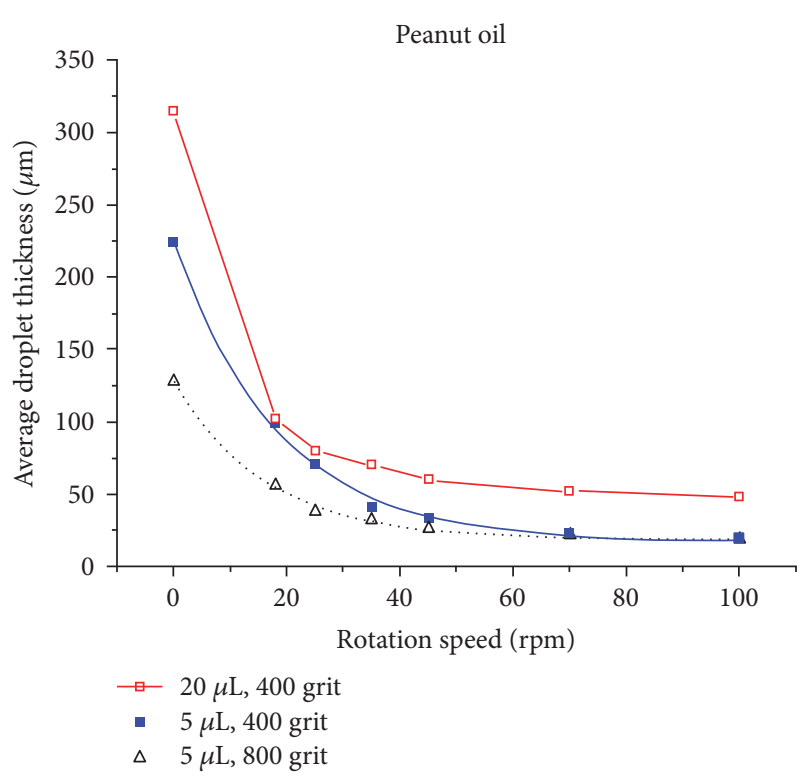

Figure 6: Average droplet thickness of peanut oil with volume of $20 \mu \mathrm{L}$ or $5 \mu \mathrm{L}$, placed on the support polished with sandpaper of 400 grits $/ \mathrm{mm}$ and 800 grits $/ \mathrm{mm}$. For $5 \mu \mathrm{L}$ droplets, the data are fitted exponentially.

film thickness. On the substrate polished by the finer sandpaper $(800$ grits $/ \mathrm{mm})$, the average liquid height is importantly lower than for the rougher polishing except at high rotation speeds, where the estimated thicknesses converge to about $20 \mu \mathrm{m}$. Here, the film height also tends to a constant value at lower rotation speed compared to the rougher substrate, where the exponential decay coefficients are $15.5 \mathrm{rpm}^{-1}$ and $18 \mathrm{rmp}^{-1}$, respectively. Comparing the Figures 4 and 6 , we might conclude that on peanut oil, the LIBS signal excited by $70 \mathrm{~mJ}$ pulses becomes stable for the thickness below $50 \mu \mathrm{m}$.

A steady diesel droplet with volume of $20 \mu \mathrm{L}$ has the thickness about twice lower than the oil droplet, and this explains the much lower RSD of the C I line (Figure 3(d)). Due to a very low kinematic viscosity, in rotation at the minimum speed (18 rpm), the large diesel droplet already spreads over the whole substrate and partially leaves it, thus compromising the calculations of the average area occupied by the liquid and so, of the film thickness. For the droplet of $5 \mu \mathrm{L}$, we estimated the thickness of $19 \mu \mathrm{m}$ at rotation speed of $18 \mathrm{rpm}$. To measure the area occupied by diesel droplet at high rotation speeds, it was necessary to reduce its volume to $0.2 \mu \mathrm{L}$ only; otherwise, the liquid volume was partially lost from the support disc. In this case, the estimated liquid thickness reaches the stable value of about $3 \mu \mathrm{m}$ at speed of only $35 \mathrm{rpm}$. Rapid thinning of diesel droplet with the rotation speed explains a drop of the RSD relative to C I line below value of 0.5 already at $18 \mathrm{rpm}$; on the oil, this value of RSD was achieved at the speeds above $40 \mathrm{rpm}$. Stability of the C I line intensity from one laser shot to another, much better on diesel than on oil (Figures 3(c) and 3(d) and Figure 4), could be attributed to large differences in the liquid film thickness.

3.2. Influence of Laser Energy on the LIBS Signal. Influence of pulse energy on the LIBS signal was studied at constant rotation speed of $40 \mathrm{rpm}$, on both diesel and peanut oil; for the latter, we used the support polished with the abrasive papers with 400 or 800 grits $/ \mathrm{mm}$. At the chosen rotation speed, the estimated thickness of diesel film was of about $3 \mu \mathrm{m}$ while peanut oil film was thick of about $40 \mu \mathrm{m}$ and $27 \mu \mathrm{m}$ for the polishing by 400 and 800 grits $/ \mathrm{mm}$, respectively. For the rougher polishing and the oil sample, by increasing laser energy, the C I line intensity starts to grow from about $50 \mathrm{~mJ}$. At the pulse energy of $190 \mathrm{~mJ}$, the C I peak is about 60 times higher than at the minimum energy used here (Figure 7(a)). Simultaneously, the growth of the Al I emission intensity is much slower compared to the $\mathrm{C} \mathrm{I}$ line, so the line intensity ratio $\mathrm{I}(\mathrm{Al}) / \mathrm{I}(\mathrm{C})$ rapidly drops from 2.0 , reaching values in range $0.1-0.2$ only (Figure $7(\mathrm{~b})$ ). This means that starting from a certain laser energy, here around $30 \mathrm{~mJ}$, the plasma produced on the liquid film effectively screens the support material from ablation and further energy increase mainly contributes to excitation of the species originating from the liquid. This fact is very important for reducing influence of the substrate's constituents on the spectra from the analyzed liquid sample. Figure 8 shows the comparative spectra from peanut oil obtained at two very different pulse energies. 


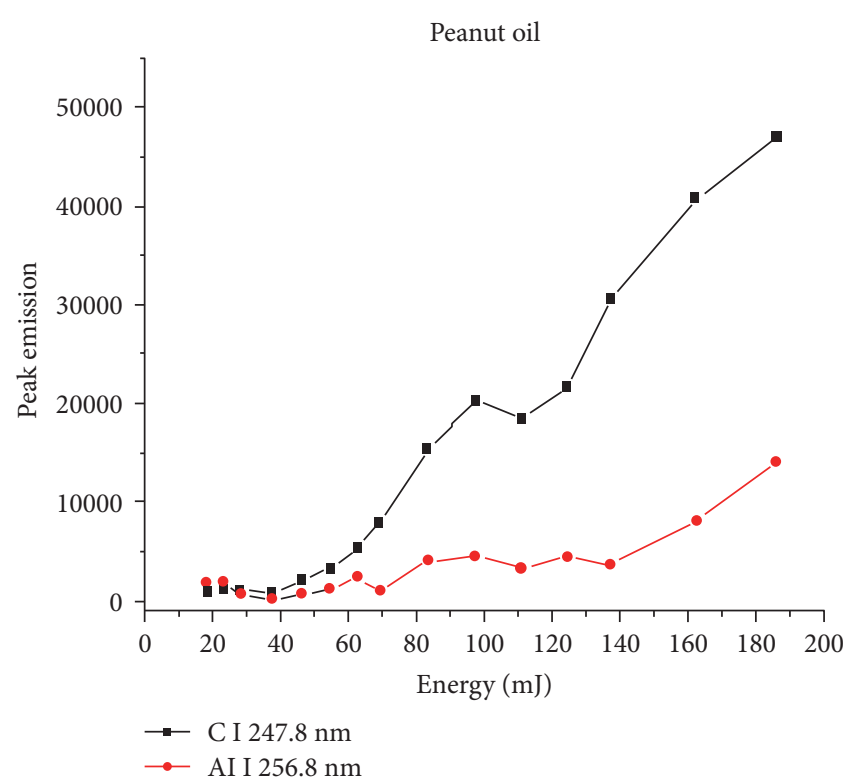

(a)

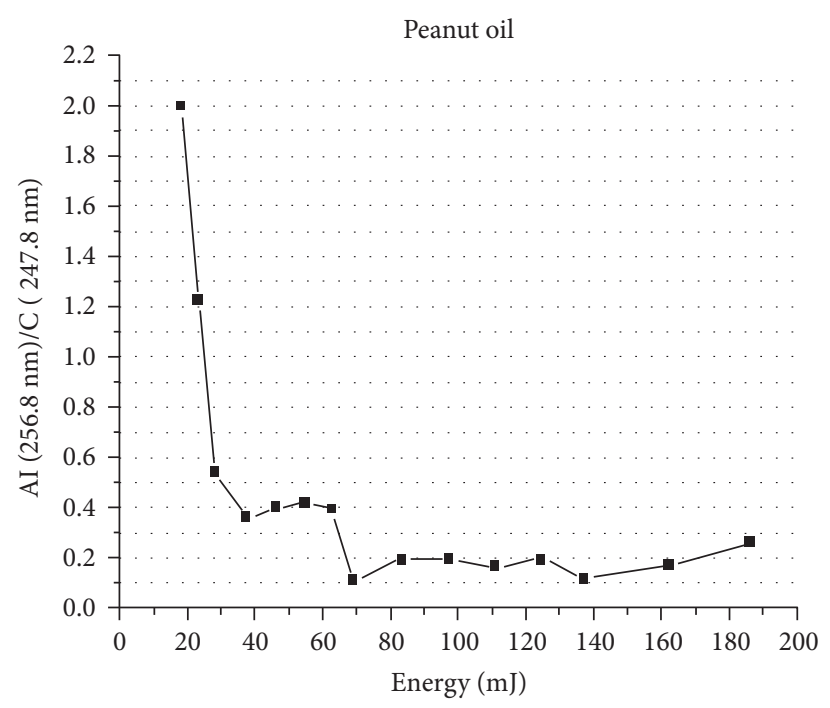

(b)

Figure 7: (a) Peak emission of C I and Al I lines averaged over 10 pulses as a function of the laser energy. (b) The corresponding line intensity ratio. The sample is peanut oil rotated at speed of $40 \mathrm{rpm}$.

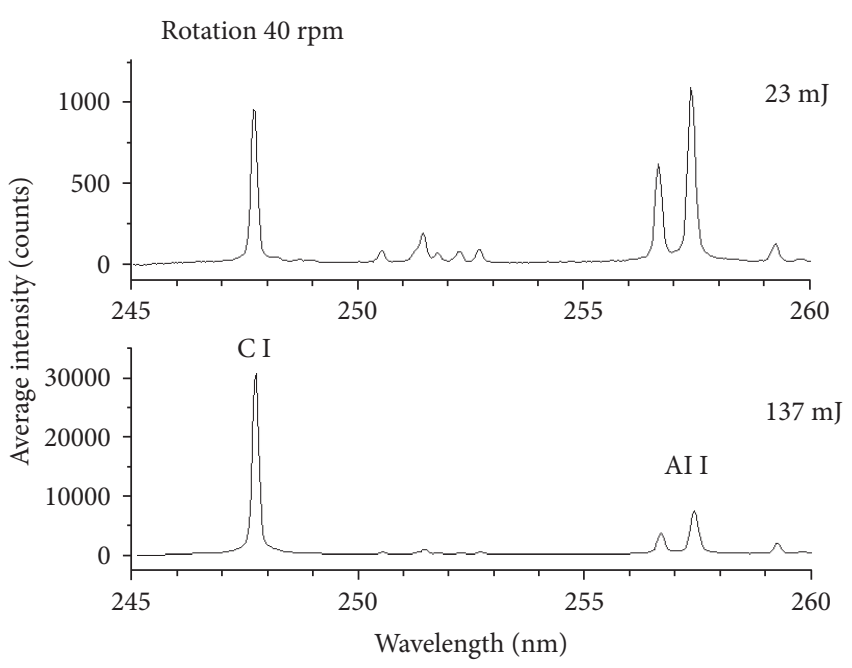

FIgURE 8: LIBS spectra from peanut oil on aluminum substrate (polishing 400 grits $/ \mathrm{mm}$ ) averaged over 10 laser pulses with energies of $23 \mathrm{~mJ}$ (top) and $137 \mathrm{~mJ}$ (bottom); the rotation speed is $40 \mathrm{rpm}$.

On peanut oil, starting from the pulse energy of about $40 \mathrm{~mJ}$, the RSD of C I line steadily decreases from value above 1.1 or 1.3 to 0.2 (Figure 9(a)). On the rougher substrate, the signal stability is initially worse than for the finer polishing, and the stable RSD is reached at higher pulse energy (125 mJ compared to $110 \mathrm{~mJ}$ ). Further increase of the laser energy corresponds to a stable RSD of C I peak in the spectrum except at the highest energy applied here $(190 \mathrm{~mJ})$, where some other instabilities seem to occur. At the same time, the RSD of $\mathrm{Al}$ peak fluctuates at high values, between 0.7 and 1.6 (not shown). On diesel film, about 10 times thinner than the oil, the intensity of C I line is much more stable from one shot to another, and an approximately constant $\mathrm{RSD} \approx 0.1$ is reached at the laser energy of about $80 \mathrm{~mJ}$. From these results, it is clear that there is a laser energy threshold $E_{\mathrm{st}}$ above which the LIBS signal from liquid film becomes stable. Basing on the previously estimated liquid film thickness and the data shown in Figure 9(a), we found a linear relation between the film thickness and the energy threshold $E_{\text {st }}$ (Figure 9(b)). We hypothesize that above the threshold energy $E_{\text {st }}$, the liquid layer locally detaches from the surface and becomes fully evaporated, resulting in a stable emission intensity from one laser shot to another and independently on a strongly variable support ablation. Further increase of the laser energy mainly contributes to the excitation of the atomized species from the liquid, without affecting importantly the support ablation (see Figure 7).

3.3. Optimization of the Experimental Conditions. Previously, we showed that the LIBS signal from an analyzed organic liquid improves in intensity and stability by reducing the liquid film thickness, achieved here by the substrate rotation. Thinning of the liquid film on substrate also reduces the laser energy requirements for obtaining an intense stable signal, and this is very important if a laser source with limited performances is used.

Unfortunately, increase of the rotation speed above a certain value does not bring significant improvements of the LIBS signal as the minimum achievable film thickness depends on kinematic viscosity of liquid, which is a measure of resistance to flow and shear. Kinematic viscosity $\eta$ of oils decreases exponentially with temperature, and it is described by the Arrhenius equation:

$$
\eta=A_{1} e^{E_{a} / R T}
$$

where $A_{1}$ and $E_{a}$ are constants specific for the oil, $R$ is the universal gas constant, and $T$ is the absolute temperature. 


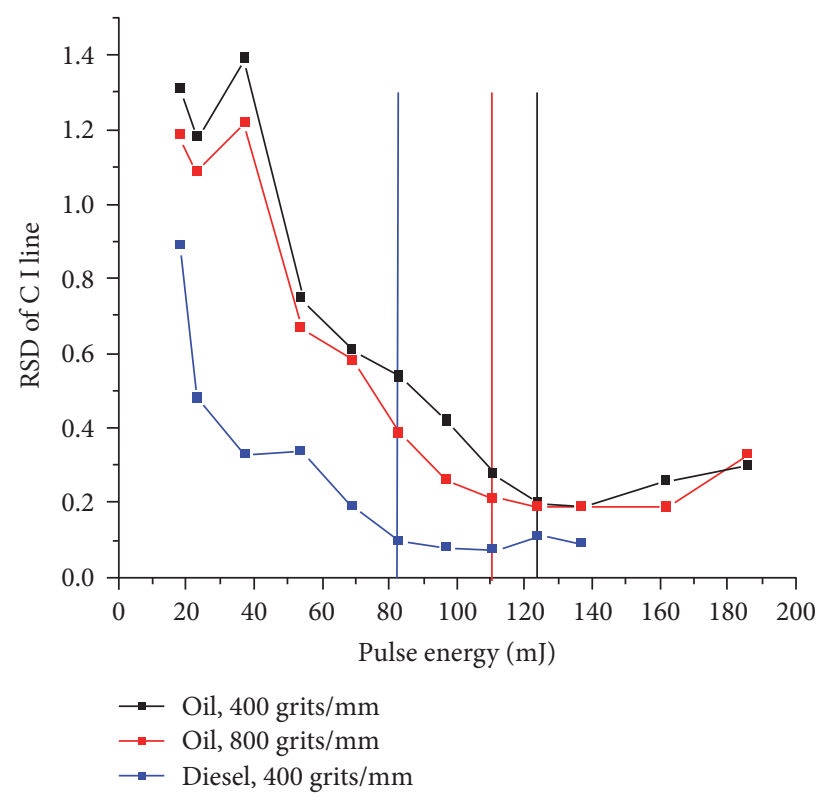

(a)

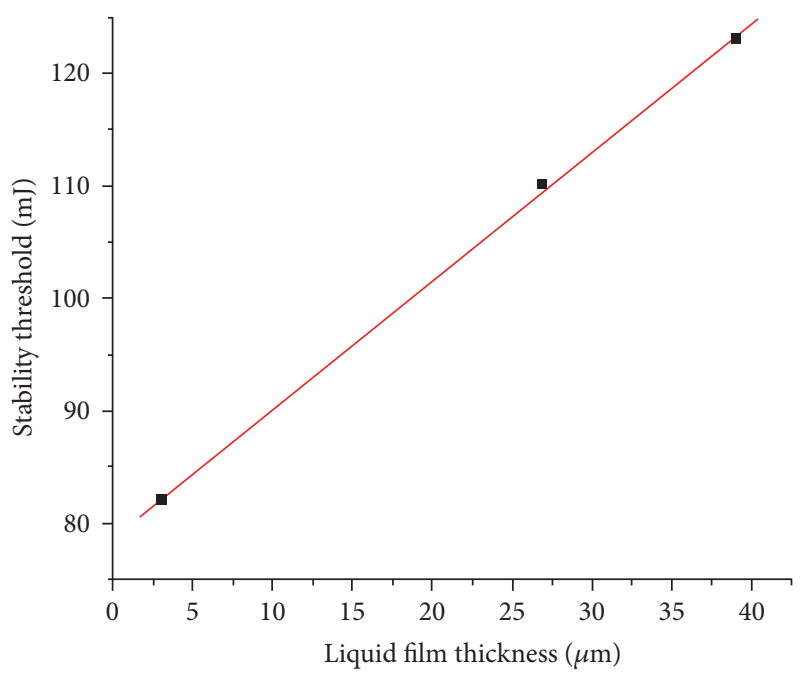

(b)

FIGURE 9: (a) RSD of C I line as a function of the laser energy at rotation speed of $40 \mathrm{rpm}$, measured on diesel (blue) and on peanut oil for two polishing grades of the substrate; the energies where the signal becomes stable are indicated with vertical lines. (b) The threshold energy for stable C I line intensity as a function of the estimated liquid film thickness.

TABLE 2: Kinematic viscosities of diesel [36], sunflower oil [36], and peanut oil [35] at different temperatures.

\begin{tabular}{lccc}
\hline \multirow{2}{*}{ Temperature $\left({ }^{\circ} \mathrm{C}\right)$} & \multicolumn{3}{c}{ Kinematic viscosity $\left(\mathrm{mm}^{2} / \mathrm{s}\right)$} \\
& Diesel & Sunflower oil & Peanut oil \\
\hline 10 & 5.4 & 118.7 & 133 \\
20 & 4.15 & 73.4 & 82 \\
30 & 3.3 & 48.5 & 54 \\
40 & 2.7 & 33.8 & 37 \\
50 & 2.3 & 24.5 & 27 \\
\hline
\end{tabular}

Table 2 shows kinematic viscosity at different temperatures for diesel and sunflower oil, published in [36], and the known or extrapolated values by (2) for refined peanut oil [35]. It is evident that close to room conditions, the kinematic viscosity of organic liquids rapidly reduces with raising the temperature. From the practical point of view, this means that a more efficient thinning of a liquid film could be achieved by keeping the sample above room temperature, for example, at $30^{\circ} \mathrm{C}$. Anyway, in order to have well-repeatable LIBS measurements, it would be opportune to keep the liquid sample at a stable temperature or to adjust the rotation speed in a way to maintain the wanted liquid film thickness.

If the rotation speed of the motor employed is limited to lower values than here $(150 \mathrm{rpm})$, the film thickness at a certain and not high rotation speed could be further reduced by finer polishing of the substrate. However, due to a simultaneous liquid atomization and the substrate ablation, for detecting the trace elements in liquids, it is necessary to use a support material free of the same, for example, silica wafer
[22]. In the case of a metallic substrate, its polishing should not transfer impurities to the material. For example, we compared the spectra from the bare aluminium substrate (not covered by a liquid) after polishing it by a sandpaper or by $\mathrm{Al}_{2} \mathrm{O}_{3}$ particles. In the first case, by sweeping the monochromator over different wavelength ranges, we detected $\mathrm{Cr}, \mathrm{Cu}$, and $\mathrm{Zr}$ lines in the spectra. These lines were not present in the LIBS spectra taken on the same substrate polished by $\mathrm{Al}_{2} \mathrm{O}_{3}$ particles, and this clearly indicates a transfer of impurities from the sandpaper grains to the substrate surface.

\section{Conclusions}

A droplet of a viscous liquid could be efficiently reduced to a thin film by rotating the support on which it is placed. In this way, the average liquid's height was reduced here from about $140 \mu \mathrm{m}$ to $3 \mu \mathrm{m}$ and from about $320 \mu \mathrm{m}$ to $20 \mu \mathrm{m}$ for droplets of diesel and peanut oil, respectively. The minimum film thickness that could be achieved at high rotation speeds is roughly proportional to the kinematic viscosity of liquid, much lower for diesel than for peanut oil.

Thinning of a liquid droplet/film eliminates unwanted laser-induced splashes and spraying during LIBS measurements, thus minimizing losses of the sample volume and a necessity to clean the nearby optical elements. Increase of the support rotation speed enhances the intensities of the spectral lines from liquid up to a factor 100 until the saturation is reached, corresponding to an almost constant liquid film thickness. The saturation speed lowers with the applied laser pulse energy.

Besides an impressive increase in the LIBS signal with thinning of a liquid film, shot-to-shot fluctuations of the line intensities originated from the liquid are reduced many 
times. A better signal stability corresponds to a thinner liquid film and to a higher pulse energy.

Raising the laser energy above a certain threshold produces a full local atomization/ionization of the liquid layer and reduces abruptly the LIBS signal fluctuations. Simultaneously, intensities of the lines originating from liquid are largely enhanced while those generated by the support ablation remain relatively weak, and this reduces the substrate interference in the spectra from the liquid sample. The threshold laser energy increases with the liquid thickness, which could be reduced also by a finer substrate polishing.

The proposed simple method for liquid analysis, together with the presented parameter optimizations here (energy, film thickness), allows to obtain a very intense and a relatively stable LIBS signal from small liquid volumes. Further studies should regard the analytical sensibility of the method and the effects of substrate material on the plasma formation.

\section{Conflicts of Interest}

The authors declare that there is no conflict of interest regarding the publication of this paper.

\section{References}

[1] D. W. Hahn and N. Omenetto, "Laser-induced breakdown spectroscopy (LIBS), part I: review of basic diagnostics and plasma-particle interactions: still-challenging issues within the analytical plasma community," Applied Spectroscopy, vol. 64, pp. 335A-366A, 2010.

[2] D. W. Hahn and N. Omenetto, "Laser-induced breakdown spectroscopy (LIBS), part II: review of instrumental and methodological approaches to material analysis and applications to different fields," Applied Spectroscopy, vol. 66, pp. 347-419, 2012.

[3] R. Fantoni, L. Caneve, F. Colao, L. Fornarini, V. Lazic, and V. Spizzichino, "Methodologies for laboratory laser induced breakdown spectroscopy semi-quantitative and quantitative analysis-a review," Spectrochimica Acta Part B: Atomic Spectroscopy, vol. 63, pp. 1097-1108, 2008.

[4] D. W. Hahn, "Laser-induced breakdown spectroscopy for sizing and elemental analysis of discrete aerosol particles," Applied Physics Letters, vol. 72, pp. 2960-2962, 1998.

[5] B. Hettinger, V. Hohreiter, M. Swingle, and D. W. Hahn, "Laser-induced breakdown spectroscopy for ambient air particulate monitoring: correlation of total and speciated aerosol particle counts," Applied Spectroscopy, vol. 60, pp. 237-245, 2006.

[6] L. A. Álvarez-Trujillo, V. Lazic, J. Moros, and J. J. Laserna, "Standoff monitoring of aqueous aerosols using nanosecond laser-induced breakdown spectroscopy: droplet size and matrix effects," Applied Optics, vol. 56, pp. 3773-3782, 2017.

[7] T. Bundschuh, T. U. Wagner, and R. Koster, "Laser-induced breakdown detection (LIBD) for the highly sensitive quantification of aquatic colloids. Part I: principle of LIBD and mathematical model," Particle \& Particle Systems Characterization, vol. 22, pp. 172-180, 2005.

[8] T. Kovalchuk-Kogan, V. Bulatov, and I. Schechter, "Optical breakdown in liquid suspensions and its analytical applications," Advances in Chemistry, vol. 2015, Article ID 463874, 21 pages, 2015.
[9] V. Lazic, "LIBS analysis of liquids and of materials inside liquids," in Laser-Induced Breakdown Spectroscopy, S. Mussazzi and U. Perini, Eds., vol. 624, Springer-Verlag, Berlin, Germany, 2014, Chap. 8.

[10] M. Yao, J. Lin, M. Liu, and Y. Xu, "Detection of chromium in wastewater from refuse incineration power plant near Poyang Lake by laser induced breakdown spectroscopy," Applied Optics, vol. 51, pp. 1552-1557, 2012.

[11] K. Rifai, S. Laville, F. Vidal, M. Sabsabi, and M. Chakera, "Quantitative analysis of metallic traces in water-based liquids by UV-IR double-pulse laser-induced breakdown spectroscopy," Journal of Analytical Atomic Spectrometry, vol. 27, pp. 276-283, 2012.

[12] S. T. Jarvinen, S. Saari, J. Keskinen, and J. Toivonen, "Detection of $\mathrm{Ni}, \mathrm{Pb}$ and $\mathrm{Zn}$ in water using electrodynamic single-particle levitation and laser-induced breakdown spectroscopy," Spectrochimica Acta Part B: Atomic Spectroscopy, vol. 99, pp. 9-14, 2014.

[13] N. E. Schmidt and S. R. Goode, "Analysis of aqueous solutions by laser-induced breakdown spectroscopy of ion exchange membranes," Applied Spectroscopy, vol. 56, pp. 370-374, 2002.

[14] L. St-Onge, E. Kwong, M. Sabsabi, and E. B. Vadas, "Rapid analysis of liquid formulations containing sodium chloride using laser-induced breakdown spectroscopy," Journal of Pharmaceutical and Biomedical Analysis, vol. 36, pp. 277-284, 2004.

[15] Y. G. Mbesse Kongbonga, H. Ghalila, M. Boyomo Onana, and Z. Ben Lakhdar, "Classification of vegetable oils based on their concentration of saturated fatty acids using laser induced breakdown spectroscopy (LIBS)," Food Chemistry, vol. 147, pp. 327-331, 2014.

[16] Z. Abdel-Salam, J. Al Sharnoubi, and M. A. Harith, "Qualitative evaluation of maternal milk and commercial infant formulas via LIBS," Talanta, vol. 115, pp. 422-426, 2013.

[17] N. H. Cheung and E. S. Yeung, "Distribution of sodium and potassium within individual human erythrocytes by pulsedlaser vaporization in a sheath flow," Analytical Chemistry, vol. 66, pp. 929-936, 1994.

[18] N. Melikechi, H. Ding, S. Rock, O. Marcano, and D. Connolly, "Laser-induced breakdown spectroscopy of whole blood and other liquid organic compounds," Proceedings of the SPIE, vol. 6863, article 68630O, 2008.

[19] N. K. Rai and A. K. Rai, "LIBS-an efficient approach for the determination of $\mathrm{Cr}$ in industrial wastewater," Journal of Hazardous Materials, vol. 150, no. 3, pp. 835-838, 2008.

[20] L. Zheng, F. Cao, J. Xiu et al., "On the performance of laserinduced breakdown spectroscopy for direct determination of trace metals in lubricating oils, Spectrochim," Spectrochimica Acta Part B: Atomic Spectroscopy, vol. 99, pp. 1-8, 2014.

[21] V. Lazic and S. Jovićević, "Laser induced breakdown spectroscopy inside liquids: processes and analytical aspects," Spectrochimica Acta Part B: Atomic Spectroscopy, vol. 101, pp. 288-311, 2014.

[22] V. Lazic, R. Fantoni, A. Palucci, and M. Ciaffi, "Sample preparation for repeated measurements on a single liquid droplet using laser-induced breakdown spectroscopy," Applied Spectroscopy, vol. 71, pp. 670-677, 2017.

[23] D. Bae, S.-H. Nama, S.-H. Han, J. Yoo, and Y. Lee, "Spreading a water droplet on the laser-patterned silicon wafer substrate for surface-enhanced laser-induced breakdown spectroscopy," Spectrochimica Acta Part B: Atomic Spectroscopy, vol. 113, pp. 70-78, 2015. 
[24] J.-S. Xiu, X.-S. Bai, V. Motto-Ros, and J. Yu, "Characteristics of indirect laser-induced plasma from a thin film of oil on a metallic substrate," Frontiers of Physics, vol. 10, pp. 231-239, 2015.

[25] H. Ohba, M. Saeki, I. Wakaida, R. Tanabe, and Y. Ito, "Effect of liquid-sheet thickness on detection sensitivity for laserinduced breakdown spectroscopy of aqueous solution," Optics Express, vol. 22, pp. 24478-24490, 2014.

[26] N. K. Rai and A. K. Rai, "LIBS-an efficient approach for the determination of $\mathrm{Cr}$ in industrial wastewater," Journal of Hazardous Materials, vol. 150, pp. 835-838, 2008.

[27] S. Zhu, Y. F. Lu, and M. H. Hong, "Laser ablation of solid substrates in a water-confined environment," Applied Physics Letters, vol. 79, 2001.

[28] H. W. Kang, H. Lee, S. Chen, and A. J. Welch, "Enhancement of bovine bone ablation assisted by a transparent liquid layer on a target surface," IEEE Journal of Quantum Electronics, vol. 42, pp. 633-642, 2006.

[29] N. Krstulović, S. Shannon, R. Stefanuik, and C. Fanara, "Underwater-laser drilling of aluminum," The International Journal of Advanced Manufacturing Technology, vol. 69, pp. 1765-1773, 2013.

[30] N. Bärch, A. Gatti, and S. Barrcikowski, "Improving laser ablation of zirconia by liquid films: multiple influence of liquids on surface machining and nanoparticle generation," Journal of Laser Micro/Nanoengineering, vol. 4, pp. 66-70, 2009.

[31] D. Kim, B. Oha, and H. Lee, "Effect of liquid film on nearthreshold laser ablation of a solid surface," Applied Surface Science, vol. 222, pp. 138-147, 2004.

[32] P. Frank, J. Graf, F. Lang, J. Boneberg, and P. Leiderer, "Laserinduced film ejection at interfaces: comparison of the dynamics of liquid and solid films," Applied Physics A, vol. 101, pp. 7-11, 2010.

[33] A. B. Chhetri and K. C. Watts, "Surface tensions of petro-diesel, canola, jatropha and soapnut biodiesel fuels at elevated temperatures and pressures," Fuel, vol. 104, pp. 704-710, 2013.

[34] N. Siddiqui and A. Ahmad, "A study on viscosity, surface tension and volume flow rate of some edible and medicinal oils," International Journal of Science, Environment and Technology, vol. 2, pp. 1318-1326, 2013.

[35] T. W. Ryan III, L. G. Dodge, and T. J. Callahan, "The effects of vegetable oil properties on injection and combustion in two different diesel engines," Journal of the American Oil Chemists Society, vol. 61, pp. 1610-1619, 1984.

[36] B. Esteban, J.-R. Riba, G. Baquero, A. Rius, and R. Puig, "Temperature dependence of density and viscosity of vegetable oils," Biomass and Bioenergy, vol. 42, pp. 164-171, 2012. 

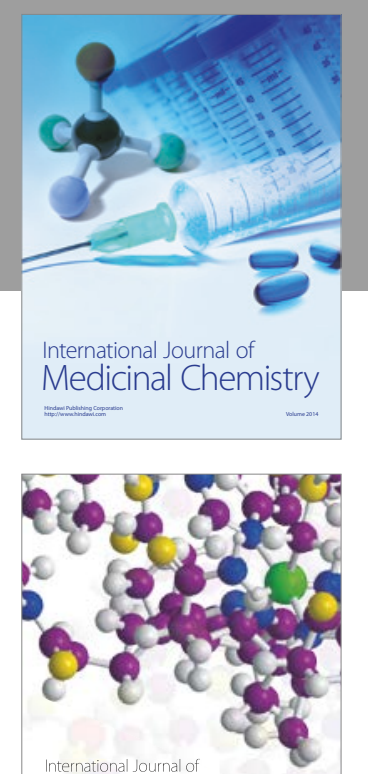

Carbohydrate Chemistry

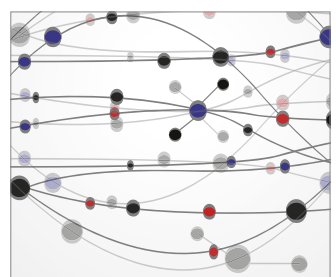

The Scientific World Journal
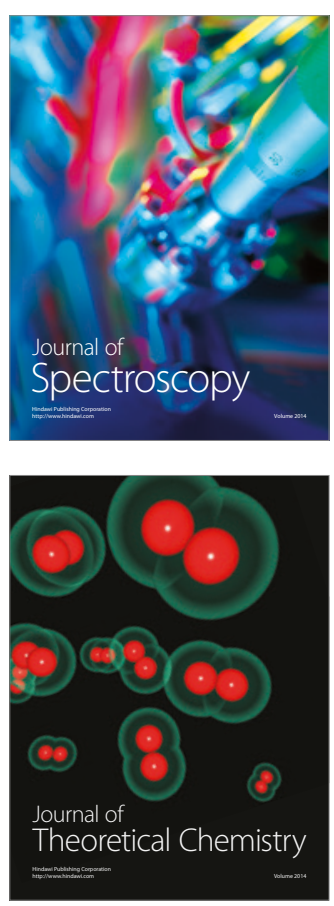
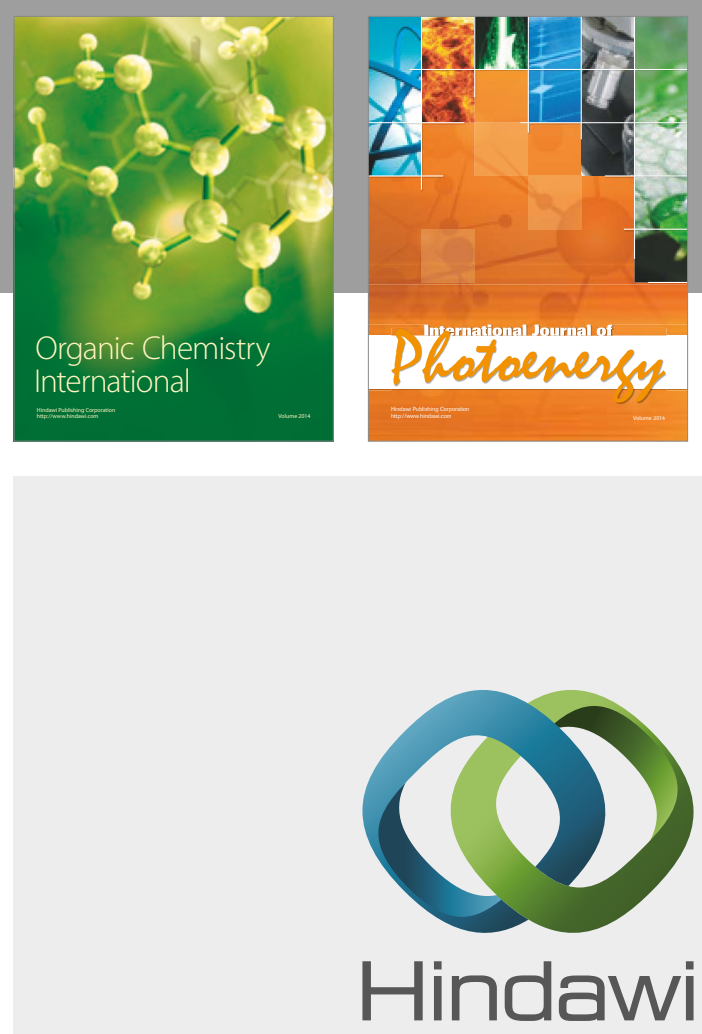

Submit your manuscripts at

https://www.hindawi.com

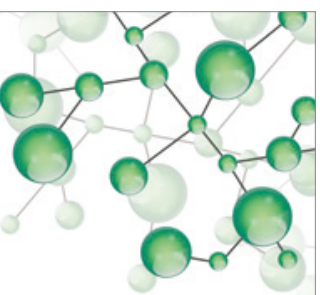

International Journal of

Inorganic Chemistry

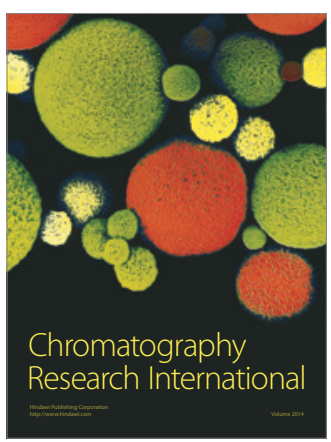

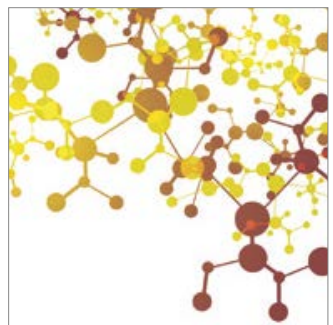

Applied Chemistry
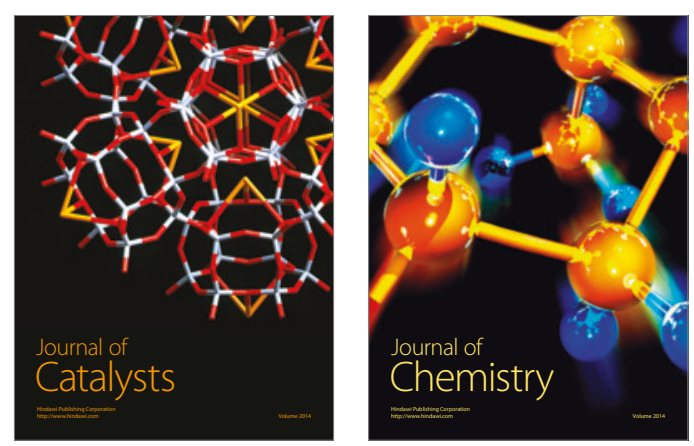
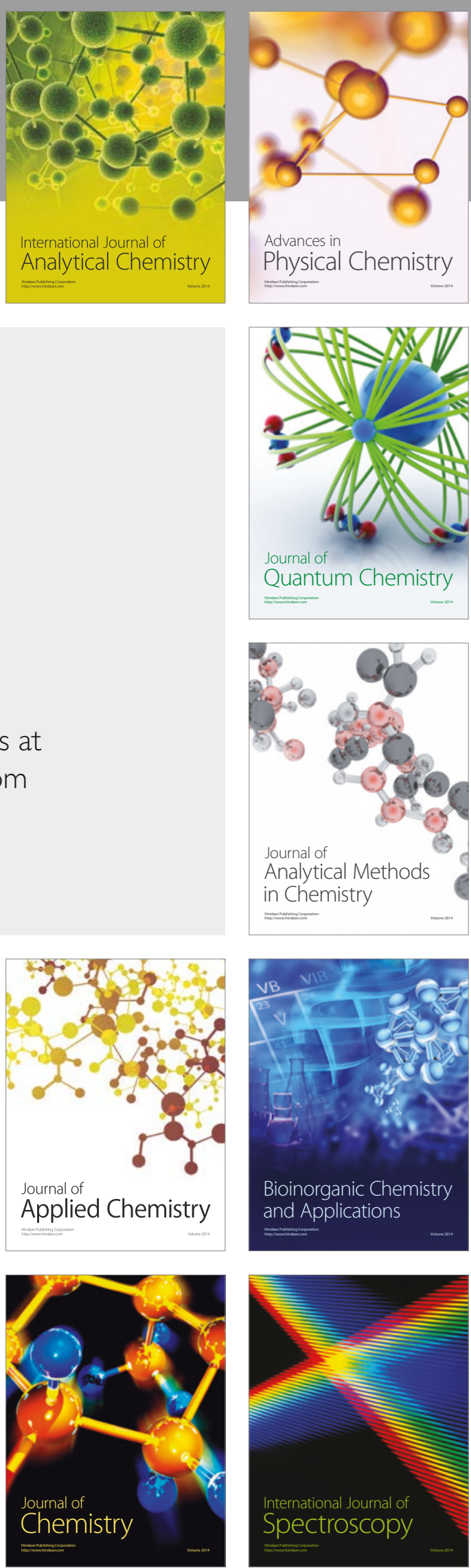